\title{
Remove Organic and Inorganic Contaminants in the Waste Oil Using MBBR, Nano Reactor and Physical Methods
}

\section{Maryam Shirinkar* and Masoud Zolanvar}

North Branch of Islamic Azad University of Tehran, Iranian Offshore Oil Company, Iran

\begin{abstract}
The aim of this study was to evaluate the performance of pilots physical, biochemical and chemical, in series and together for waste water treatment plants, processing oil in the Persian Gulf's oil and gas. For this purpose a Skimmer tank, MBBR reactor, Nano reactor, UV tank was used. Incoming wastewater system effluent desalination unit. Hydraulic retention time for various different system is intended. If you reduce the retention time of 18 to 12 hours, removed COD from $91 \%$ to $76 \%$ reduced. It was also found that the total removal of carbon materials in part MBBR $78.2 \%$ and $21.8 \%$ of the biofilm floating microorganisms. The results indicate that the whole system, which consists of 4 pilot that each part of its eliminates COD in waste water, the ability to remove $91 \%$ of COD. Solution input load $1.766 \mathrm{Kg} \mathrm{COD} / \mathrm{m}^{2}$ was signed. Finally, after the passage of treated wastewater and filters in 4 stages, has a relatively uniform quality and desirable.
\end{abstract}

Keywords: MBBR; Skimmer tank; Organic; Nano reactor; COD; Wastewater

\section{Introduction}

Waste water is a problem in oil industry. Over the last decades there has been a growing interest in biofilm processes for waste water treatment. Moving bed biofilm reactor (MBBR) is an efficient alternative for organic carbon and nitrogen removal which combine the advantages of both the active sludge process and a biofilm reactor by incorporating free-floating carriers that provide a large surface area for colonization with no need for biomass recycling [1].

There are several reasons for the fact that biofilm processes often are being increasingly favored instead of activated sludge processes, such as the following:

a. The treatment plant requires less apace.

b. The final treatment result is less dependent on biomass separation since the biomass concentration to be separated is at least 10 times lower.

c. The attached biomass becomes more specialized (higher concentration of relevant organisms) at a given point in the processes train, because there is no sludge return.

There are already many different biofilm systems in use, such as trickling filters, rotating biological contactors (RBC), fixed media submerged biofilters, granular media biofilters, fluidized bed reactors etc.

They have all their advantages and disadvantages. The trickling filter is not volume-effective.

Mechanical failures are often experienced with the RBC'S.It is difficult to get distribution of the load on the whole carrier surface in fixed media submerged biofilters. The granular media biofilters have to be operated discontinuously because of the need for backwashing and the fluidized bed reactors show hydraulic instability [2].

Among various semiconductors, $\mathrm{TiO}_{2}$ is one of the most efficient photocatalyst for the degradation of pollutants in aqueous suspension through the photogenerated strong oxidizing agents like hydroxyl radical and superoxide radical anions under UV light irradiation. It is pertinent to mention here that $\mathrm{TiO}_{2}$ can only be excited by UV light due to its large band gap energy (3.2 ev for anatase) which is not ideal to absorb visible light.

To overcome this problem research groups working in the area of photocatalysis are trying to extend the optical response of photocatalyst from UV to visible region by doping it with metal or non-metal into the $\mathrm{TiO}_{2}$ lattice.

The various methods used for doping $\mathrm{TiO}_{2}$ involve ion implantation, sol-gel reaction, hydrothermal reaction, solid-state reaction, etc.

Among these, one of the sol-gel processed is undoubtedly the simplest and the cheapest one which provides control on the size and shape of nano particles [3].

Few studies relating to the synthesis of molybdenum (Mo), Manganese $(\mathrm{Mn})$ and $\mathrm{Zinc}(\mathrm{Zn})$ doped $\mathrm{TiO}_{2}$ using different methods and its photocatalytic activity for the degradation of pollutants have been reported earlier. For example, in two separate studies Modoped $\mathrm{TiO}_{2}$ has been synthesized using thermal hydrolysis and sol-gel method, In another study by Devi etal. $\mathrm{Mn}$-doped $\mathrm{TiO}_{2}$ was synthesized using sol-gel process and its photocatalytic activity was investigated by studying the degradation of a dye derivative amaranth. On the other hand, synthesis of $\mathrm{Zn}$-doped $\mathrm{TiO}_{2}$ using different methods and their activity for the degradation of dyes and organic pollutant has been reported in the literature [3].

Waste water with high levels of organic matter (COD) Phosphorous $(\mathrm{P})$ and Nitrogen $(\mathrm{N})$ cause several problems, such as eutrophication, oxygen consumption and toxicity, when discharged to the environment.

Biological processes are a cost-effective and environmentally sound alternative to the chemical treatment of waste water.

*Corresponding author: Maryam Shirinkar, North Branch of Islamic Azad University of Tehran, Iranian Offshore Oil Company, Iran, E-mail: Shirinkar.Maryam@yahoo.com

Receive December 28, 2016; Accepted January 20, 2016; Published January 27,2016

Citation: Shirinkar M, Zolanvar M (2016) Remove Organic and Inorganic Contaminants in the Waste Oil Using MBBR, Nano Reactor and Physical Methods. J Pet Environ Biotechnol 7: 268. doi:10.4172/2157-7463.1000268

Copyright: @ 2016 Shirinkar M, et al. This is an open-access article distributed under the terms of the Creative Commons Attribution License, which permits unrestricted use, distribution, and reproduction in any medium, provided the original author and source are credited. 
Citation: Shirinkar M, Zolanvar M (2016) Remove Organic and Inorganic Contaminants in the Waste Oil Using MBBR, Nano Reactor and Physical Methods. J Pet Environ Biotechnol 7: 268. doi:10.4172/2157-7463.1000268

Biological processes based upon suspended biomass (i.e., activated sludge processes) are effective for organic carbon and nutrient removal in municipal waste water plants. But there are some problems of sludge settleability and the need for large reactors and setting tanks and biomass recycling. Biofilm reactors are especially useful when slow growing organisms like nitrifies have to be kept in a waste water treatment process.

During the past decade, it has been successfully used for the treatment of many industrial effluents including pulp and paper industry waste, poultry processing waste water, cheese waste, phenolic waste water, dairy waste water and municipal waste water [4].

This paper proposes a new methodology for treatment waste water. This study, there for, set out to assess the effect of Moving Bed Bio Reactor (MBBR), and the effect of Nano particle of $\mathrm{TiO}_{2}$ doped $\mathrm{Mn}, \mathrm{Mo}, \mathrm{Zn}$ and UV lamp to removing oil in waste water.The present research explores, for the first time, the effect of Skimmer tank and MBBR and Nano particle in reactor and UV lamp (4 system) on waste water of oil industry. Due to practical constraints, this paper cannot provide a comprehensive review of removing oil from waste water with 4 systems. It is my experience of working with skimmer tank, MBBR, Nano particle, UV that has driven this research.

This paper begins by introducing Skimmer tank, it will then go on to MBBR system and Nano reactor, then UV, finally it will deal with removal of free oil and decreasing COD in waste water.

\section{Material and Methods}

A Schematic of pilot process concept is shown in Figure 1, where the treatment train consists of 2 tanks and 2 reactors.

\section{The skimmer tank}

In the Skimmer tank, remove oil free from the surface of waste water. The input current is entered at rate of $1 \mathrm{lit} / \mathrm{hr}$.

\section{The biofilm reactor (MBBR)}

Carriers: In the MBBR, the biomass grows on carriers that move freely in the water volume by aeration [5]. The biofilm carriers are made of high-density polyethylene (density $0.95 \mathrm{~g} / \mathrm{cm}^{3}$ ). The size of the carrier varies from lengths of 7-15 mm and diameters of $10-15 \mathrm{~mm}$. The carrier filling fraction (percentage of reactor volume occupied with carriers in empty tank) is normally $60-70 \%$ [5]. The Kaldnes carriers have a specific gravity of 0.96 with a specific biofilm protected surface area of $500 \mathrm{~m}^{2}$ per $\mathrm{m}^{3}$ bulk volume of carriers. The Kaldnes biofilm carrier element is illustrated in Figure 2 [6].

Lab-scale reactor and waste water: A Laboratory scale Plexiglas with total liquid volume of 2 lit in the study (Figure 3). Diffusers were used for oxygen supply and mixing. The dissolved oxygen (Do) concentrations in the MBBR ranged from 0.2 to $5.00 \mathrm{mg} \mathrm{o}_{2} /$ lit depending on the influent organic loading rates. The temperature and $\mathrm{PH}$ in the reactor varied from 28 to $31 \mathrm{c}$ and 6.72 to 7.88 , respectively [6] and the pressures varying between 0.1 and 0.5 bar [5].

Waste water: Effluent entering the fourth stage was the output unit $2 \mathrm{Ft}$ in height desalter of Kharg Island in Iranian offshore Oil Company. In Figure 4 and Table 1, GC taken combined effluent shows. Synthetic oil was mixed with waste water in laboratory. The effluent from the first stage of the pilot project, from the skimmer tank to sign the final phase, removal and cleaning after several phases and the water from final phase was uniform and satisfactory quality and standard of environment. The calculated COD/N/P ratio of the syntheticwaste water was 100/5/1 [6]. The waste water was enriching with the macro-nutrients by adding

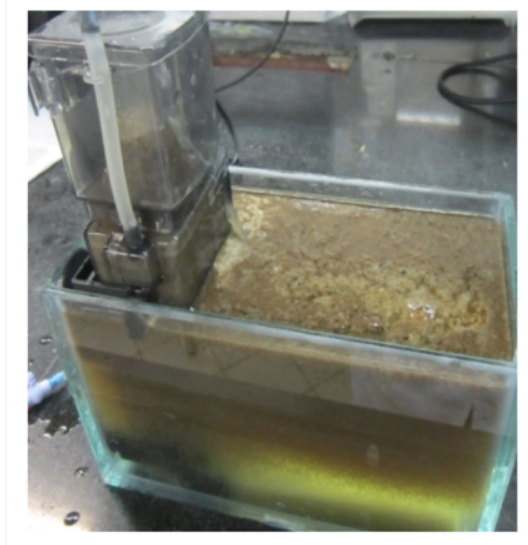

Figure 1: Skimmer tank.

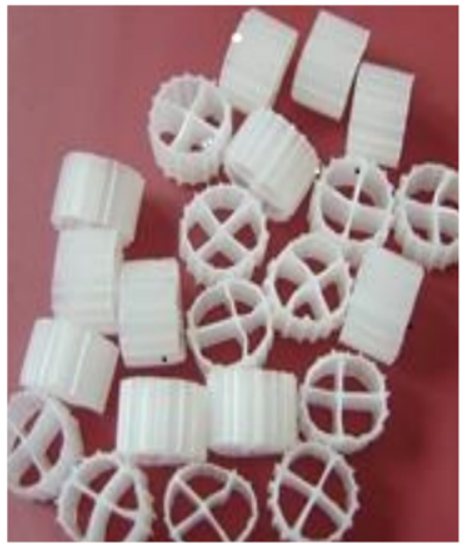

Figure 2: Media K2.

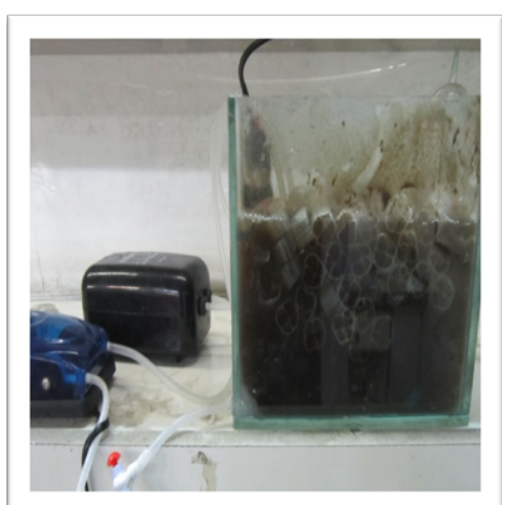

Figure 3: MBBR reactor.

urea as nitrogen source and $\mathrm{K}_{2} \mathrm{HPO}_{4}$ as phosphorus source [4]. NH-N ranged from $25-125 \mathrm{mg} / \mathrm{lit}$ and po4-p ranged from $5-25 \mathrm{mg} / \mathrm{lit}$ were prepared and used as feed to the systemBy the way, vermin-compost leachate was used for injection and enrichment of waste water.

\section{Nano reactor}

Synthesis $\mathrm{TiO}_{2}$ doped $\mathrm{Mn}$, Mo, Znnano particle: $\mathrm{TiO}_{2}$ nano particles were synthesized by sol-gel method using Titanium tetra 


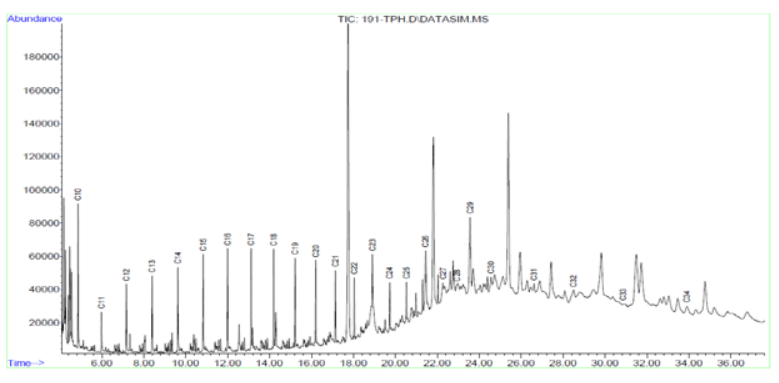

Figure 4: Gc pattern of wastewater.

\begin{tabular}{|c|c|c|c|c|}
\hline No & $\begin{array}{l}\text { Compound } \\
\text { Name }\end{array}$ & RT (min) & Units & Amount \\
\hline 1 & C10 & 4.863 & ppm & 1.304 \\
\hline 2 & C11 & 5.978 & ppm & 0.420 \\
\hline 3 & C12 & 7.167 & $\mathrm{ppm}$ & 0.617 \\
\hline 4 & C13 & 8.398 & ppm & 0.736 \\
\hline 5 & C14 & 9.622 & ppm & 0.732 \\
\hline 6 & C15 & 10.83 & ppm & 0.825 \\
\hline 7 & C16 & 11.996 & ppm & 0.884 \\
\hline 8 & C17 & 13.116 & ppm & 0.921 \\
\hline 9 & C18 & 14.19 & $\mathrm{ppm}$ & 0.883 \\
\hline 10 & C19 & 15.217 & ppm & 0.876 \\
\hline 11 & $\mathrm{C} 20$ & 16.198 & ppm & 0.798 \\
\hline 12 & C21 & 17.139 & ppm & 0.732 \\
\hline 13 & C22 & 18.032 & ppm & 0.603 \\
\hline 14 & $\mathrm{C} 23$ & 18.897 & ppm & 1.448 \\
\hline 15 & C24 & 19.727 & $\mathrm{ppm}$ & 0.459 \\
\hline 16 & $\mathrm{C} 25$ & 20.522 & ppm & 0.544 \\
\hline 17 & C26 & 21.439 & ppm & 1.759 \\
\hline 18 & $\mathrm{C} 27$ & 22.263 & ppm & 0.686 \\
\hline 19 & $\mathrm{C} 28$ & 22.931 & ppm & 0.122 \\
\hline 20 & C29 & 23.558 & ppm & 2.662 \\
\hline 21 & C30 & 24.556 & ppm & 0.623 \\
\hline 22 & C31 & 26.611 & ppm & 0.034 \\
\hline 23 & C32 & 28.485 & ppm & 0.049 \\
\hline 24 & C33 & 30.853 & ppm & ND \\
\hline 25 & C34 & 33.895 & ppm & 0.021 \\
\hline 26 & C35 & 0 & ppm & ND \\
\hline
\end{tabular}

Table 1: The output unit $2 \mathrm{Ft}$ in height desalter of Kharg Island in Iranian offshore Oil Company.

isopropoxid (TTIP) as titania precursor and doped with different concentrations of Molybdenum (Mo), Manganese (Mn) and Zinc ( $\mathrm{Zn}$ ) $(0.5-1 \%)$ and characterized by standard analytical techniques such as $\mathrm{x}$-ray diffraction (XRD) and scaning Electron Microscopy (SEM). The $\mathrm{XRD}$ analysis shows the partial crystalline nature and Rutile phase (Figure 5). The SEM images of doped $\mathrm{TiO}_{2}$ at different magnifications also show the partial crystalline nature with rough surfaces (Figure 6).

Coating $\mathrm{TiO}_{2}$ doped $\mathrm{Mn}, \mathrm{Mo}, \mathrm{Zn}$ in nano filter: $\mathrm{TiO}_{2}$ doped nano particles were coated on filter plates Whatsman N.34 and placed in an oven for 24 hours at a temperature of 34-42 c, pages was ready to install in reactor.

Nano rector: A schematic of pilot process concept is shown in Figure 7. Doped nanoparticles on pages tray tower, when in fact these pages are filters that were built for the job, coats and waste water passes on these plates, such as fluid flow in the distillation tower. On plates waste water dealing with these nano particles, mass transfer and removal of organic contaminants and treatment is better.

\section{UV tank}

A schematic of pilot process concept is shown in Figure 8. Treated wastewater from step 1 to 3 , enter UV-Tank, and in the presence of UV light rays with a wavelength of $280-100 \mathrm{~nm}$, refined and wastewater output has reached that limit environmental standards and can be used for watering plants and entering the environmental and sea. Data management and analysis were performed using SPSS, Xpert and Excle.

\section{Results and Discussion}

Experimental work in the laboratory was carried out in order to evaluate the efficiency of the system for the removal of organic matter and relationship between organic removal and abserved yield using a high loaded MBBR and Nano reactor.

Effluent total COD and COD removal rates versus time in Skimmer tank, MBBR, Nano reactor, UV-tank are show in Figure 9.

The XRD, SEM patterns of doped $\mathrm{TiO}_{2}$ with $\mathrm{Mo}, \mathrm{Mn}, \mathrm{Zn}$ calcinated at $550 \mathrm{c}$ for $4 \mathrm{~h}$ were analyzed [3].

All deped $\mathrm{TiO}_{2}$ particles showed that particle crystalline nature and Rutile phase [3].

The average rutile crystallite size of doped and undoped $\mathrm{TiO}_{2}$ nano particles was determined by Debye Scherer formula:

$$
\mathrm{D}=\mathrm{K}^{\star} \gamma / \mathrm{B}^{\star} \operatorname{Cos} \mathrm{Q}
$$

Where $\mathrm{D}$ is the crystallite size, $\mathrm{K}$ the shape factore, $\gamma$ the wavelength, $\mathrm{Q}$ the diffraction angle and $\mathrm{B}$ is the full width at half maximum [3].

The XRD, SEM is shown in Figures 5 and 6.

\section{COD analysis}

COD analysis in skimmer tank: An oil skimmer continues to remove oils as long as they are present. Depending on oil influx rate and the oil skimmer's removal rate, residual oil in the water maybe as low as a few parts per million. When residual oil reaches this level and further reduction is required, it may be more pratical to use a secondary removal method following skimming, such as MBBR.

COD analysis in MBBR: In order to observe the quality of the aqueous solution, chemical oxygen demand (COD) measurements were also carried out before and after the MBBR. As demonstrated in Figure 10 increasing inlet concentration up to $800 \mathrm{mg} / \mathrm{l}$ did not significantly affect the performance of the MBBR in COD removal and the efficiencies were over $91 \%$ for this parameter, although further increasing inlet concentration showed an adverse effect on the removal

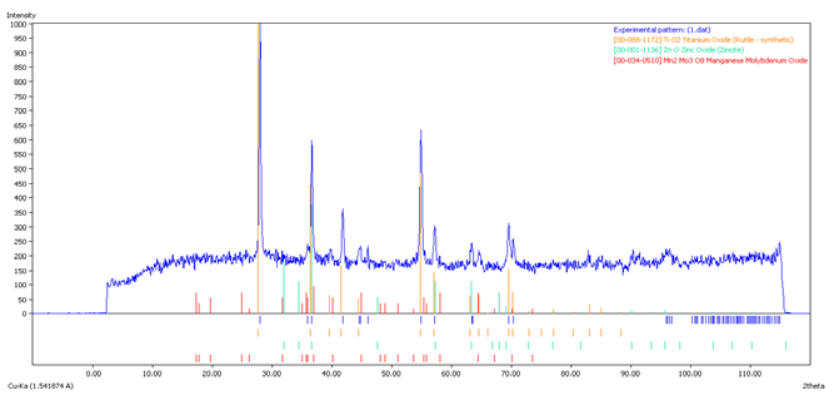

Figure 5: XRD patterns of $\mathrm{Tio}_{2}$-doped $\mathrm{Mn}, \mathrm{Mo}, \mathrm{Zn}$. 
Citation: Shirinkar M, Zolanvar M (2016) Remove Organic and Inorganic Contaminants in the Waste Oil Using MBBR, Nano Reactor and Physical Methods. J Pet Environ Biotechnol 7: 268. doi:10.4172/2157-7463.1000268
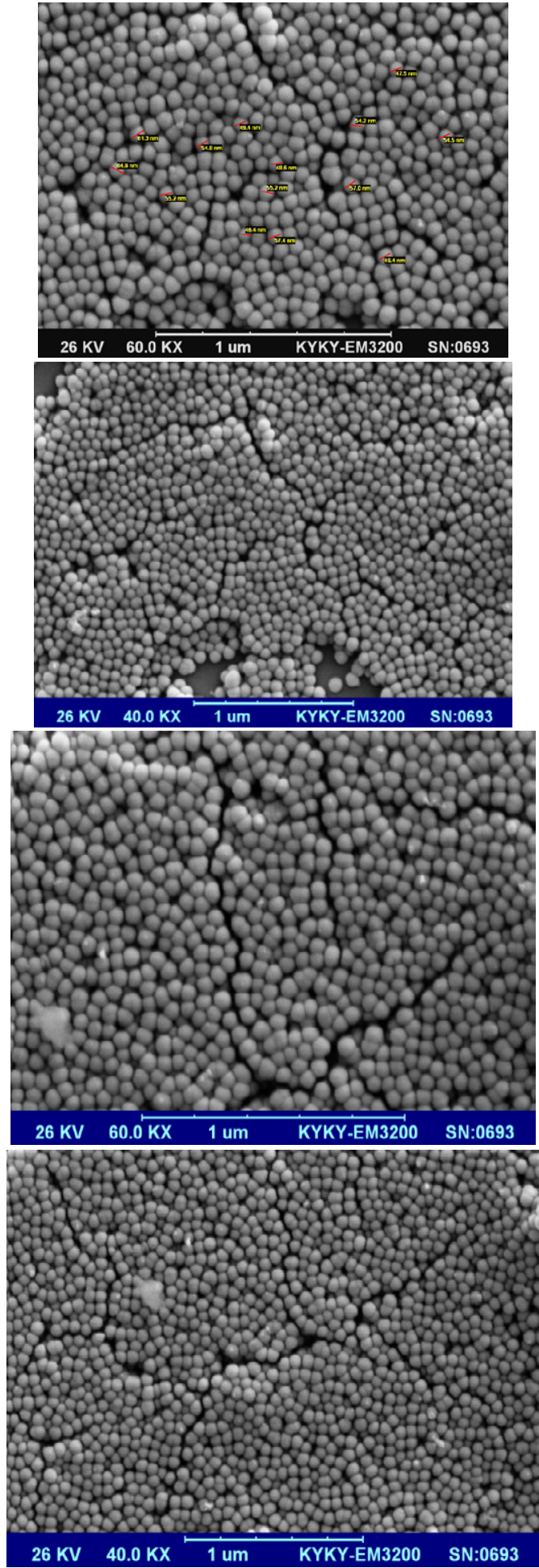

Figure 6: SEM images of $\mathrm{Tio}_{2}$-doped $\mathrm{Mn}, \mathrm{Mo}, \mathrm{Zn}$.

efficiency particularly, increasing inlet concentration to 1000 and 1400 $\mathrm{mg} / \mathrm{l}$ resulted in decreasing COD removal $91 \%$ respectively.

Therefore the optimum surface loading rate based on inlet concentration (at HRT of $18 \mathrm{~h}$ ) on the MBBR was found to be $6.62 \mathrm{~g}$ $\mathrm{COD} / \mathrm{m}^{2}$.day. Accordingly, the MBBR could effectively remove organic and inorganic contaminants in waste water, (Figures 10 and 11).
Figure 10 shows that organic and inorganic contaminants and COD removal efficiencies were not affected by reducing HRT down to $18 \mathrm{~h}$ and removal efficiencies of both parameters were greater than $91 \%$.

The effect of salt content of wastewater ranging from $10 \mathrm{~g} / \mathrm{l}$ to 70 $\mathrm{g} / \mathrm{l}$ was assessed on the behavior of the MBBR under the previously optimized conditions given in Table 2.

COD analysis in NANO reactor: A COD measurement by a photocatalytic oxidation sol-gel method using nano $\mathrm{TiO}_{2}$ doped was investigated. In order to observe the quality of the aqueoues solution, chemical oxygen demand (COD) measurements were also carried out before and after the treatment.

A significant decrease in the COD values was observed, which clearly indicates that the photocalytic method offers good potential for the removal of organic and inorganic contaminants wastewater.

COD analysis in UV-tank: UV-VIS spectroscopy was suggested as fast and versatile monitoring tools for BOD and COD in water samples. This spectroscopy has also advantage of limiting measurements time for BOD from 5 days to few minutes and also limiting the usage of a large amount of expensive reagents. Absorbance of UV in wastewater to removal organic and inorganic contaminants shown in Figure 11.

\section{Conclusion}

4-steps process studied in this research, including pilot Skimmer tank, MBBR, Nano reactor and UV-tank that is, the ability to remove the COD has been quite successful.The amount MLSS rise, the resistance reactors against fluctuations will increase. The COD and organic and inorganic contaminants in wastewater much reduced in this 4 steps and process applicable on an industrial scale operation.

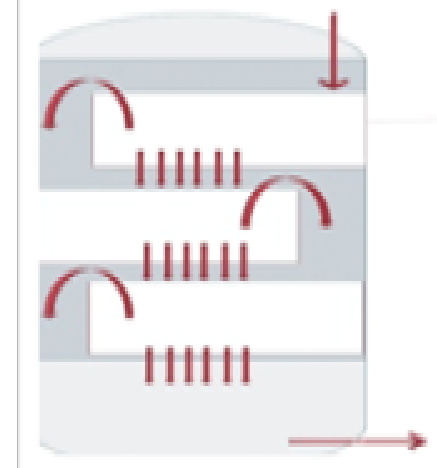

Figure 7: Nano reactor.

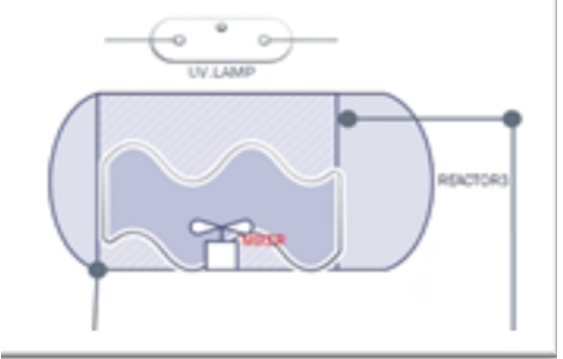

Figure 8: UV-tank. 
Citation: Shirinkar M, Zolanvar M (2016) Remove Organic and Inorganic Contaminants in the Waste Oil Using MBBR, Nano Reactor and Physical Methods. J Pet Environ Biotechnol 7: 268. doi:10.4172/2157-7463.1000268

Page 5 of 5

\begin{tabular}{|c|c|c|c|c|c|}
\hline \multicolumn{6}{|c|}{ Experimental phases and MBBR operation timing schedule } \\
\hline Phase & Day & Operation & $C_{\text {in }}(\mathrm{mg} / \mathrm{L}) \mathrm{COD}$ & Salt content (g/L) & HRT(b) \\
\hline 1 & $0-90$ & Biomass acclimation & 107.5-1075 & $0-30$ & - \\
\hline 2 & $91-150$ & Effect of $C_{\text {in }}$ & $430-2580$ & 30 & 24 \\
\hline 3 & $151-190$ & Effect of HRT & 1720 & 30 & $8-24$ \\
\hline 4 & $191-245$ & Effect of salt content & 1720 & $10-70$ & 18 \\
\hline 5 & $246-247$ & Response to organic shock loading & - & 30 & 18 \\
\hline 6 & $248-249$ & Response to hydraulic shock loading & 1720 & 30 & - \\
\hline 7 & $250-251$ & Response to salt shock loading & 1720 & - & 18 \\
\hline
\end{tabular}

Table 2: COD analysis in MBBR.

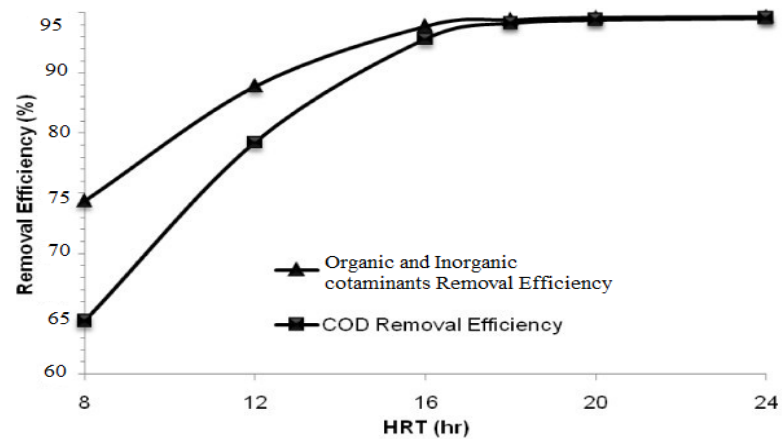

Figure 9: Graph analysis of COD.

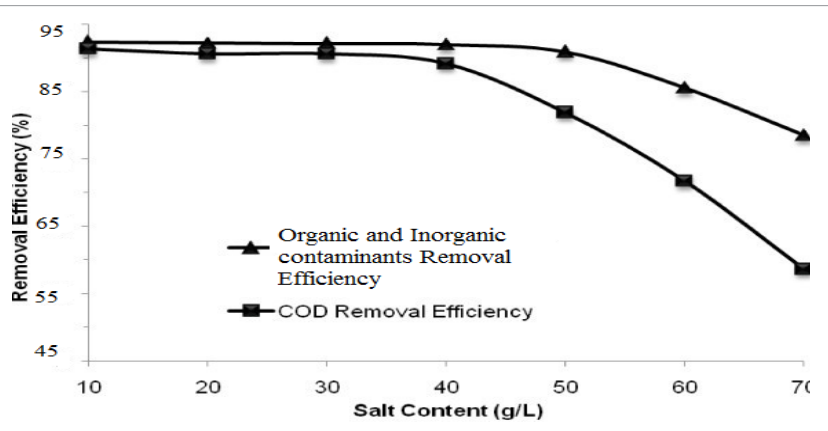

Figure 10: Graph analysis of COD.

\section{Acknowledgements}

Authors would like to acknowledge Iranian Offshore Oil Company; Nano Company for the financial support provided this work.
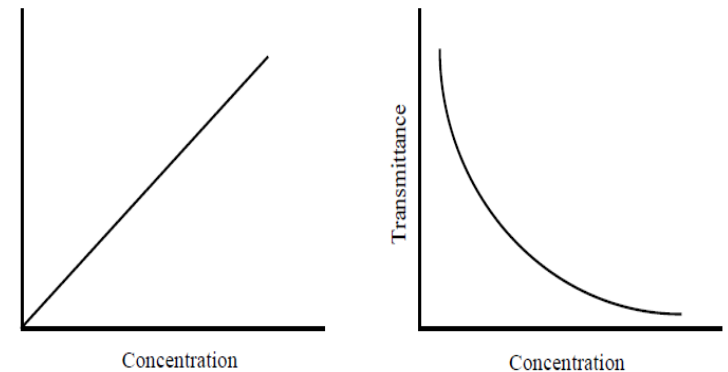

Absorbance and transmittance of photon plotted v-s concentration of solutions

Figure 11: Graph Analysis of UV-tank.

\section{References}

1. Zinatizade AAL (2012) Separation of nitrophenols using cellulose acetate nanofiltration membrane: Influence of surfactant additives. Separat Purif Technol 85: 147-156.

2. Qdegaard H (1999) The Moving Bed Biofilm Reactor. Hokkaido Press. pp: 250-305.

3. Umar K (2013) Mo, Mn and La doped $\mathrm{Tio}_{2}$ : Synthesis, characterization and photocatalytic activity for the decolourization of three different chromophoric dyes. Journal of Alloys and Compounds 578: 431-438.

4. Kermani M, Bina B, Movahedian H, Amin M, Nikaein M (2008) Application of Moving Bed Biofilm Process for Biological Organics and Nutrient Removal from Municipal wastewater. American Journal of Environmental Sciences 4: 675-682.

5. Leiknes T (2005) The development of a biofilm membrane bioreacto Desalination 202: 135-143.

6. Aygun A (2008) Influence of High Organic Loading Rates on COD Removal and Sludge Production in Moving Bed Biofilm Reactor. Environmental Engineering Science 25: 1311-1316. 